\section{Reluctance to change and end psychotherapy}

\author{
John E. Berg \\ Faculty of Health Sciences, Oslo and \\ Akershus University Hospital, Oslo, \\ Norway
}

\begin{abstract}
Reluctance to change therapy has clinical and economic implications. Therapists are expected to deliver treatment in a oneto-one setting ending up with patient improvement. Such an achievement is difficult to overview. There is great uncertainty as to what works in psychotherapies despite research efforts. Prolonged treatment duration with little positive effect may be caused by factors inherent in therapist and patient and the external environment. Two cases are discussed illustrating the need for better surveillance of what happens in the therapy room. Responsibility for the progress in therapy rests on the shoulders of the therapist. When therapy becomes detrimental to patient and therapist, we do not have a comprehensive system to interfere or help. Delayed recovery emanates as an increase in costs to society and the family. This is the case when return to work after treatment is partly or completely retarded.
\end{abstract}

\section{Introduction}

Psychotherapy is the principal part of treatment of mental disorders, with or without the use of psychotropics. Psychotherapy was from its start around 1880 a relationship in the treatment room between a patient and a therapist, being a psychiatrist, psychologist or other mental health educated person. ${ }^{1}$ The qualifications needed to call you a psychotherapist differ between countries. Remuneration of the therapist may be from the public or private purse, treatment pro bono being a rarity. National Health Service or a private health service provider may cover the costs almost all the way as in Norway or partly or within a limit as in the USA. How much the patient must pay will influence the type of therapy chosen and its duration. Access to long term individual psychotherapy is restricted to a non-random section of the population.

Psychopharmacological treatment entered the field of individual therapy much later as relevant medication was not available before the 1950th. Some therapists still refrain from prescribing tablets.
Medications for mental disorders are often given for a time limited period only in cases of neurotic disorders, whereas medication for psychotic disorders would be needed for a prolonged, often life long period. An end to psychotherapy sessions is not defined. To become attached to therapy and the therapist is to suffer the possibility of loss. ${ }^{2}$ Some therapies are given with a fixed duration defined by the therapy type chosen (short term cognitive therapy, short term intensive psychotherapy, psychoanalysis and other) or out of economic reason. The latter is often demanded by health insurance companies or restrained by public polyclinics. ${ }^{3}$ The time in therapy is a set figure, not necessarily related to remission or other clinical end points.

On the other hand, there are psychotherapies that do not follow the described pattern. These therapies simply do not end. They are of two kinds, outlined through two cases below. The putative reasons for this are then discussed.

The material consists of two representative cases from the resident patient experience of the author. A Pub-Med search of scientific articles in several languages was performed. Search items were long-term psychotherapy, life-long psychotherapy, ending psychotherapy, uncertainty in psychotherapy. No relevant articles were retrieved. Some articles that were judged as tangentially relevant are presented in the discussion.

\section{Case Report \#1}

This patient is a 45 years old male journalist who is married with two children. $\mathrm{He}$ started in psychoanalytic therapy five years ago with weekly sessions. His depressive state continued through the therapy sessions and gradually worsened, making him unable to do his work. He displayed a passive-aggressive attitude to conflicts and withdrew from family and work social life. Giving up therapy sessions seemed too daring although he realized later that he did not improve the last two years of therapy. His wife became more and more concerned and demanded other treatment options. He was finally referred to an acute psychiatric facility. A diagnosis of bipolar disorder, present state severe depression was confirmed. He had not received relevant medications and was in a state necessitating electroconvulsive treatment (ECT). Consenting to this treatment he subsequently received a series of 10 treatments. He rapidly improved. He could then be sent home and he resumed his work. The author has subsequently followed him for the last seven years. He has
Correspondence: John E. Berg, Oslo and Akershus University Hospital, Pilestredet 48. 0130 Oslo, Norway.

Tel.: +47.67235000 .

E-mail: john@pong.no,john-erik.berg@hioa.no

Key words: Psychotherapy, duration, individual practice, cost effectiveness.

Conflict of interest: the author declares no potential conflict of interest.

Received for publication: 3 April 2017. Revision received: 15 August 2017.

Accepted for publication: 16 August 2017.

This work is licensed under a Creative Commons Attribution-NonCommercial 4.0 International License (CC BY-NC 4.0).

(C) Copyright J.E. Berg, 2017

Licensee PAGEPress, Italy

Mental Illness 2017; 9:7167

doi:10.4081/mi.2017.7167

taken lamotrigin 200 to $300 \mathrm{mg}$ per die and he has not had a relapse of severe depression.

\section{Case Report \#2}

The other patient is a 34 years old female teacher. She is unmarried and without children. During the last four years, she attended psychotherapy sessions with a psychologist. There was a strong dependence between patient and therapist. The patient may be described as disorganizedly attached to the therapist. This was revealed as severe deterioration of her state when the therapist went on holidays for some 2-3 weeks. The patient was thus referred to an inpatient clinic as the therapist feared a suicide if the patient had no psychotherapy session every week. The therapist showed signs of over-involvement and treatment insecurity towards the patient in talks with the receiving psychiatrist in the ward. During her inpatient stay suicidal ideation or plans were not present and the patient denied having them. Next year she was again referred to the acute facility when her therapist had her vacation. A histrionic personality was present in the patient.

\section{Discussion and Conclusions}

The two cases were referred for further treatment in an acute psychiatric facility after a long period in ambulatory 
therapy. Although it would be preposterous to infer that the prolonged ambulatory treatment had no discernible effect on the patients, the outcome was not satisfactory. In the first case the therapist continued for two years with psychotherapy disregarding the fact that the patient deteriorated and became inert and unable to work and participate in his usual social settings. Inpatient electroconvulsive treatment alleviated his serious depression and he returned to full time work after less than two months. In the second case therapist and patient developed a so dependent relationship that the therapist did not dare to leave her without therapy sessions for three weeks. And the patient felt so dependent on the sessions that losing out some was hard to bear. Thus, the referral to the acute department, most probably came out of the unrest the therapist felt. After consulting the medical records, referrals for this purpose from the same therapist had happened before.

The paucity of published articles on unnecessary long psychotherapy and on keeping patients in therapy because both therapist and patient do not believe that the patient can manage without is remarkable. There are, however, several studies involving randomized controlled trials and observational studies on long-term psychodynamic psychotherapy (LTPP). ${ }^{4}$ One of them is a meta-analysis where the authors show the effectiveness of long-term psychodynamic psychotherapy in patients with complex mental disorders from 11 RCTs and 12 observational studies. In another metaanalysis published 4 years after the former study, the authors found limited or conflicting effects of LTPP. 5 Ending therapy has been studied as relevant for the psychoanalytic interpretation of termination of therapy. ${ }^{6}$ Ending therapy may as outlined by Frank be interpreted as a separation process, probably both for patient and therapist. Patient reasons for ending therapy or not are elucidated in a lengthy paper by Holmes although he is mostly preoccupied with the position of the patient. ${ }^{2}$

Psychotherapists may improve with time and experience, but the results of a large study of 6591 patients and 170 therapist, indicate small changes. ${ }^{7}$ Many years of continued therapy may not result in improved outcome in patients, as illustrated by the two cases presented.

An indication of failed therapies may be what Bucci et al. wrote in a paper from 2016.8 They investigated 30 clients and 42 therapists by self-report on the attachment styles related to the working alliance. A significant association was found between insecure attachment and alliance in more symptomatic clients. The second case may be such an example. When therapists used more immediacy in a session, clients gave higher scores on session quality in a study of 164 sessions. ${ }^{9}$

The burden on the families of the patients is high. ${ }^{10}$ Financially this is often not detected as the families use resources on the patient that they otherwise would have had at free disposal. The patient in the first case got a series of ECT after terminating psychotherapy and then returned to work as many other patients getting ECT for a depressive disorder. ${ }^{11}$

Some researcher underscore that therapist effect lies in the combination of professional and personal functioning emanating as professional self-doubt. ${ }^{12}$

Patients get treatment at a certain level of the treatment chain. Treatment in single outpatient private practice may be hard to oversee or control. ${ }^{13}$ It is difficult to decide whether a patient needs a very long treatment period or whether the period is prolonged as described in the cases above. Quality control of private single person therapy does not occur before the patient or for instance hospital staff call the health authorities. Deliberate misconduct or even lack of expertise would be difficult to prove. Both therapists continued in good faith. The studies referred to indicate difficulties in deciding what effective psychotherapeutic treatments must include. Individual therapists get little guidance from existing literature and guidelines. Whether reluctance to change or end therapy is a substantial problem is anybody's guess. Therapies lasting for many years are influenced by life events outside the therapy room. These events may have a positive effect on the therapy, or alleviate adverse events. It would be desirable if therapists had easier access to qualified advice on the progress of the therapy along the lines described by Jeremy Holmes. This could help the therapist to improve the quality of therapies given, and thereby reduce the risk of not ending a therapy or not changing it. Some countries organize within the medical or psychiatric societies discrete consultations between therapists and approved colleagues on such matters.

\section{References}

1. Shorter E, ed. A history of psychiatry. From the Era of the Asylum to the Ages of Prozac. New York: John Wiley \& Sons; 1997.

2. Holmes J. Termination in psychoanalytic psychotherpay: an attachment perspective. Eur J Psychoanal 2009. Available from: http://www.journalpsychoanalysis.eu/termination-in-psychoanalytic-psychotherapy-an-attachment-perspective-2/

3. Hargreaves WA, Shumway M, Hu TW, et al. Cost-outcome methods for mental health. 1 ed. San diego: Academic Press; 1998.

4. Leichsenring F, Rabung S. Effectiveness of long-term psychodynamic psychotherapy. A meta-analysis. JAMA 2008;300:1551-65.

5. Smit Y, Huibers M, Ioannidis J, et al. The effectiveness of long-term psychoanalytic psychotherapy - a meta-analysis of randomized controlled trials. Clin Psychol Rev 2012;32:81-92.

6. Frank G. Termination revisited. Psychoanal Psychol 1999;16:119-29.

7. Goldberg SB, Miller SD, Nielsen SL, et al. Do psychotherapists improve with time and experience? A longitudinal analysis of outcomes in a clinical setting. J Couns Psychol 2016;63:1-11.

8. Bucci S, Seymour-Hyde A, Harris A, et al. Client and therapist attachment styles and working alliance. Clin Psychol Psychother 2016;23:155-65.

9. Shafran N, Kivlighan D, Gelso C, et al. Therapist immediacy: the association with working alliance, real relationship, session quality, and time in psychotherapy. Psychother Res 2016:1-12.

10. Fadden G, Bebbington P, Kuipers L. Caring and its burdens. A study of the spouses of depressed patients. $\mathrm{Br} \mathrm{J}$ Psychiatry 1987;151:660-7.

11 Berg JE. Benefits of returning to work after ECT. JECT 2013;29:29-32.

12. Nissen-Lie H, Rønnestad M, Høglend P, et al. Love yourself as a person, doubt yourself as a therapist? Clin Psychol Psychother 2017;24:48-60.

13. Husby R, Østberg B, Hartvig P. Får psykiatriske pasienter behandling på riktig omsorgsnivå? Tidsskr Nor Lægeforen 